\title{
Research of the effectiveness of mechanical testing methods with analysis of features of destructions and temperature effects
}

\author{
A.V. Babushkin, D.S. Lobanov, A.V. Kozlova, I.D. Morev \\ Perm National Research Polytechnic University, 614990, Komsomolsky av., 29, Perm, Russia \\ bav651@yandex.ru
}

\begin{abstract}
In this paper is carried out the comparative analysis of effectiveness of test methods of determination of stiffness and strength properties of highly filled unidirectional fiberglass (Direct "E" roving 0.7 - orthophthalic polyester resin 0.3 ) via tensile testing along the reinforcement and three-point bending testing at several bases. The necessity of deviation from standard procedures is substantiated. Deformation and failure features of the material under quasi-static loading, as well as at low and high temperatures, are shown.
\end{abstract}

KEYWORDS. Composite materials; Highly filled fiberglass; Test methods; Deformation and failure; High and low temperature.

\section{INTRODUCTION}

$\mathrm{F}$ or designing and providing reliable operation of high loaded shell structures from layered-fiber cross-reinforced composites are relevant issues of an adequate definition of effective elastic and strength properties of the material. These issues are usually resolved with help of mathematical modeling or tests. In this case, the structuralphenomenological modeling should be also based on the test determination of properties and features of the mechanical behavior of structural components of the composite. For modeling of a cross-reinforced fiberglass are most relevant properties of texture layer - that is a unidirectional fiber composite. Determination of unidirectional fiber composite properties is usually based on ASTM D 3039. In the test research of composite materials in the product is convenient to use method of beam-specimens bending on different bases, as this method allows determine the longitudinal strength and elastic modulus, shear modulus and shear (interlayer) strength [1]. According to this method, the properties are determined by three-point bending testing on different bases of beam-specimens, which are cut in the appropriate direction of finished product. This approach allows take into account technological features of the material production into product. However, this method gives obviously lower results, as work conditions of relatively short reinforcing fibers in cut specimen and continuous fibers in the product are significantly different. Anyway, in both cases, the result is based on test data. In practice, the lower results at test are interpreted as a certain margin of safety in product designing. Naturally, questions of estimation of this stock value and the adequacy of various test methods for providing structural mathematical modeling on the one hand, and product design in the framework of phenomenological approaches - on the other, arise.

In this paper is held a comparative analysis of different methods of test determination of unidirectional fiberglass stiffness and strength properties, deformation and fracture characteristics of these materials under quasi-static loading and also at low and high temperatures. 


\section{MATERIALS AND CONDITIONS OF TEST}

\section{Uniaxial tensile testing of unidirectional fiberglass}

$\checkmark$ ests of unidirectional fiberglass (Direct "E" roving 0.7 - orthophthalic polyester resin 0.3 ) were carried out in the direction of reinforcement. This material has main feature, which is high $(70 \%)$ content of the reinforcing component. Increase of fibers volume fraction increases material strength in the direction of the reinforcement and a sharp decrease in strength in the transverse direction. The desire to test at high and low temperatures imposes certain restrictions on the size of the specimen. These circumstances lead to restrictions on the usage of standard approaches and methods (ASTM D 3039 / D 3039M-08) for the material testing.

The grip in a form of sleeve has been designed and produced specifically for uniaxial tensile testing along the reinforcement. One of the device features is the lack of cross-compression in the gripping part of the specimen [2]. Unidirectional fiberglass specimen is made in a form of rod with a constant cross section. A specimen is holding in gripping area by adhesion, while it is being deformed and failed. Strength of this design is determined by the properties of the adhesive and the depth of the immersion. In this case, specimen length with the steel gripping sleeve is limited by working area of a temperature chamber. On the specimen gage length were applied labels for using non-contact extensometer Instron AVE, as shown in Fig. 1.

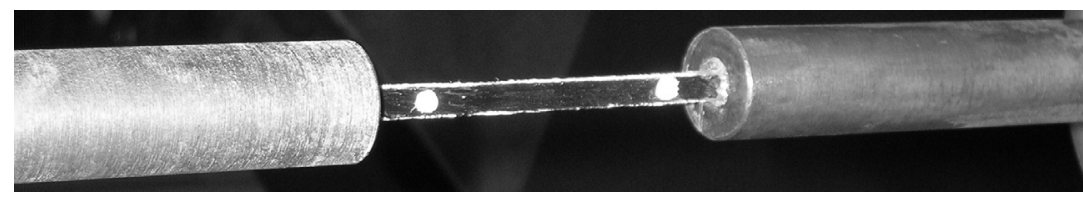

Figure 1: The appearance of highly filled fiberglass specimen for uniaxial tensile test with applied labels for using non-contact extensometer Instron AVE [2]

Tensile tests of unidirectional fiberglass along the reinforcement were held on a universal electromechanical system Instron 5882 with video extensometer Instron AVE. Climate chamber Instron 3119-407 was used at low and high temperatures tests. On Fig. 2 are shown testing system Instron 5882 (1), video extensometer (2) and a climatic chamber (3), and a specimen of the proposed construction in grips at tensile test at room temperature $\left(22^{\circ} \mathrm{C}\right)$. The necessity of a non-contact extensometer is explained by fracture behavior of specimens, which are made from this material.

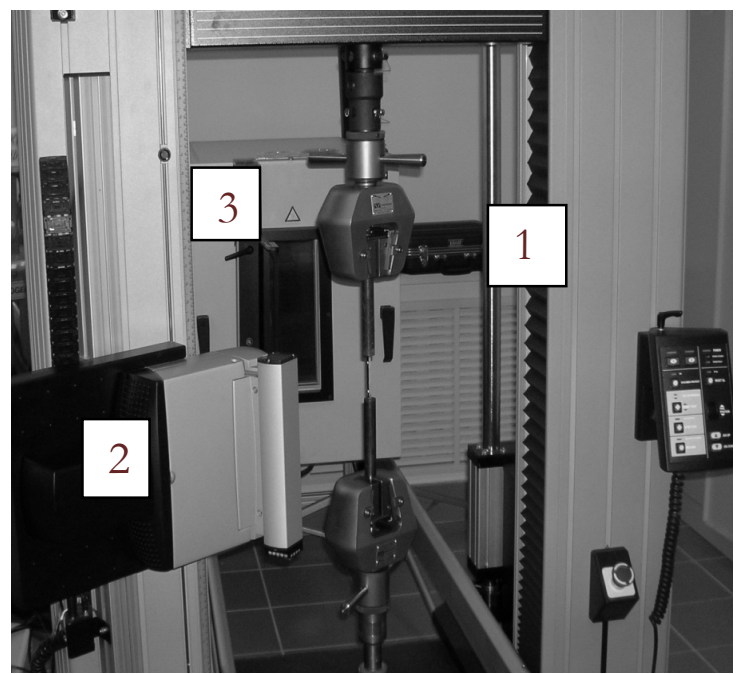

Figure 2: The appearance of the unidirectional fiberglass specimen in grips at tensile tests: Instron 5882 test set (1), video extensometer (2), climate chamber (3).

Twelve specimens were tested at room temperature. At low temperature were tested only 8 unidirectional fiberglass specimens: 4 specimens at $30^{\circ} \mathrm{C}, 4$ specimens at $0^{\circ} \mathrm{C}$. At high temperatures, were tested three specimens at each temperature of $40^{\circ} \mathrm{C}$ and $50^{\circ} \mathrm{C}$. It should be noted, that the usage of sleeves and epoxy binder as an adhesive at high 
temperatures sometimes leads to the failure, which happens in form of creep of rod out sleeves without fiber failure of the specimen. For providing the compactness of the general assembly and for determination of fiberglass stiffness and strength properties was made an attempt of using upgraded grip-sleeves, shown in Fig. 3. [2] The essence of this device is to have a tapered hole, through which was expected to create a uniform compliance (glue) cross-compression of rod specimen at tension test. However, this test circuit didn't always provide a positive result. So, ultimate tensile strength of fiberglass (Direct "E" roving 0.7 - orthophthalic polyester resin 0.3 ) at $50^{\circ} \mathrm{C}$ in this test wasn't determined.
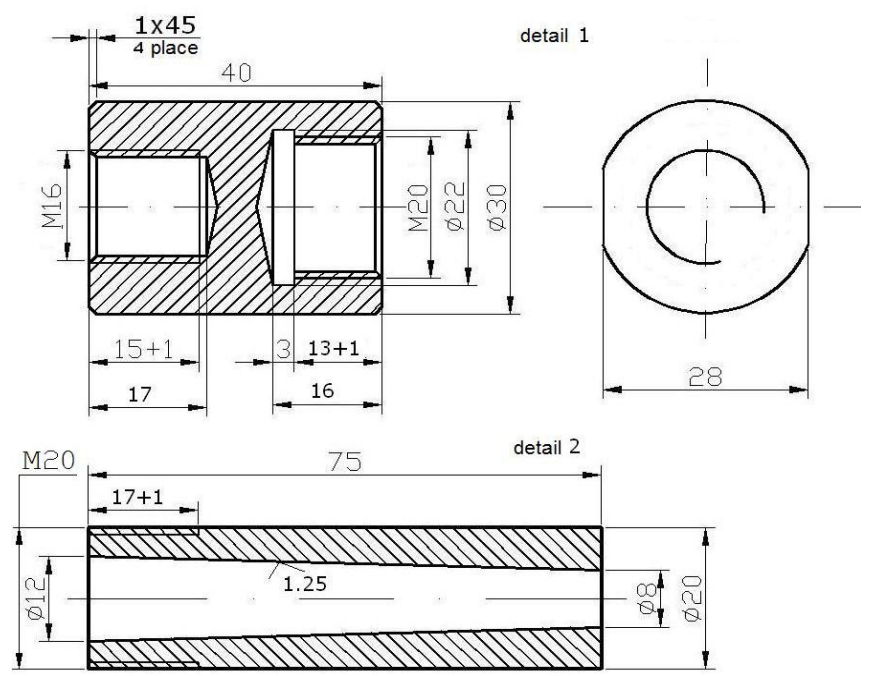

Figure 3: Scheme of device for unidirectional rod specimen testing at high temperatures [3]

Types of diagrams of unidirectional fiberglass (Direct "E" roving 0.7 - orthophthalic polyester resin 0.3 ) deformation in tensile test at various temperatures came out similar. On Fig. 4 is shown typical diagram of unidirectional fiberglass deformation in tensile test with usage of videoextensometer Instron AVE.

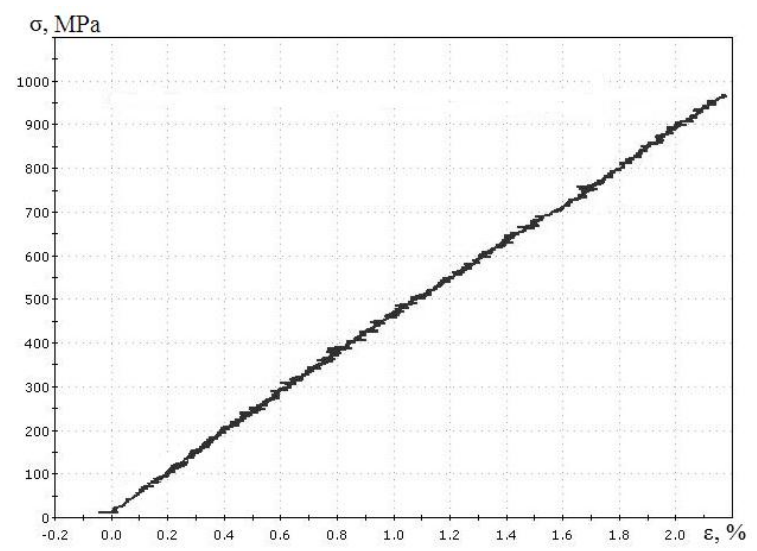

Figure 4: The appearance of typical diagram of unidirectional fiberglass Direct "E" roving 0.7 - orthophthalic polyester resin 0.3 deformation in tensile test.

Thus, as a result of specimen testing of highly filled unidirectional fiberglass on uniaxial tensile along the direction of reinforcing at room, low and high temperatures, have been identified elastic and strength characteristics of the material.

\section{Three-point bending testing of unidirectional fiberglass}

Main characteristics of unidirectional composite were also determined at bending tests. Tests were carried out by threepoint bending method of beam specimens with various lengths between brackets. For calculation of mechanical characteristics were used mathematical tools for anisotropic materials [1]. Testing scheme is shown on the Fig. 5. In whole 
testing technique is similar to ASTM D2344. At this case, fiberglass (Direct "E" roving 0.7 - orthophthalic polyester resin $0.3)$ specimens were cut along reinforcement in a form of beams with cross section $5 \times 5 \mathrm{~mm}$. Three specimens were tested on each of four bases: $1_{1}=30 \mathrm{~mm}, 1_{2}=50 \mathrm{~mm}, 1_{3}=70 \mathrm{~mm}, 1_{4}=100 \mathrm{~mm}$. Specimen lengths respectively were defined like $\mathrm{L}_{\mathrm{i}}=\mathrm{l}_{\mathrm{i}}+\mathrm{l}_{\mathrm{i}} / 5$. By the results of tests were made force-displacement diagrams. Mechanical characteristics calculations from test results of three specimens on one base were averaged.

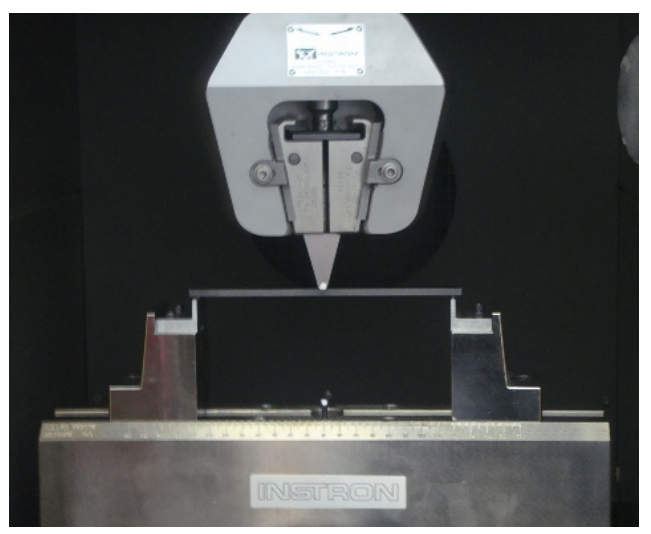

Figure 5: Bending test of unidirectional fiberglass (Direct "E" roving 0.7 - orthophthalic polyester resin 0.3 ).

\section{THE PROCESSING OF THE EXPERIMENTAL DATA}

$\mathrm{F}$

rom uniaxial tension test could be determined the ultimate tensile strength $\sigma_{\mathrm{b}}$, elastic modulus $\mathrm{E}$ and Poisson's ratio $v$. In this case, tensile strength and Young's modulus were determined [2]. Necessary stress and strain for these characteristics calculations were on gage length. Ultimate tensile strength was determined by formula

$$
\sigma_{b}=\frac{P_{\max }}{F}
$$

where $P_{\max }$ - maximum force at specimen deformation, $F$ - initial cross section area of gage length. Longitudinal deformations were measured by non-contact videoextensometer Instron AVE and were calculated by formula

$$
E=\frac{\Delta \sigma}{\Delta \varepsilon}
$$

where $\Delta \sigma$-increment of stress on linear region of deformation curve, $\Delta \varepsilon$ - corresponding increment of specimen linear deformation.

For calculation of elastic and strength characteristics at bending of fiberglass specimens was used improved theory [1]. In addition to the normal stress in the bent beam there are tangential stresses, influence of which on the strength and stiffness of isotropic composites is negligible. At bending tests of anisotropic beams, depended on the nature of the failure of specimen, can be determined flexural strength or strength at interlaminar shear. In practice, both normal and shear stresses are working in the specimen, so the determination of the properties of anisotropic composite materials at bending should take into account their mutual influence.

The adjusted formula for determination of maximum of normal stress $\sigma_{b}$ at bending has the following form

$$
\sigma_{b}=\sigma_{f}\left(1+\frac{\chi^{2}}{15}-\frac{\chi^{4}}{525}\right)
$$

and for determination of maximum of shear stress $\tau_{b}=\tau_{f}\left(1-\frac{\chi^{2}}{60}+\frac{\chi^{4}}{12600}\right)$,

where $\sigma_{f}=\frac{3}{2} \cdot \frac{P_{\max } \cdot l_{i}}{b b^{2}}$ and $\tau_{f}=\frac{3}{4} \cdot \frac{P_{\max }}{b h}$, so $\chi=\frac{\pi b}{2 l_{i}} \cdot \sqrt{\frac{E_{f}}{G}}-$ parameter of anisotropy, $E_{f}-$ fictitious elastic modulus; $G$-interlayer shear modulus; $b$ - specimen width, $l_{i}$-length between brackets at three-point bending. 
For defying elastic modulus at three point bending of laminate composite material should be used refined dependencies, which consider influence of shear deformations and binding maximum flexure $\omega_{\max }$ of the beam in the middle of brackets with applied force $\mathrm{P}$, true elastic modulus at bending $E_{f}^{t}$ and interlayer shear modulus $G$ :

$$
\omega_{\max }=-\frac{P \cdot l_{i}^{3}}{48 E_{f} I}\left(1+\alpha_{k}\left(\frac{h}{l_{i}}\right)^{2} \frac{E_{f}}{G}\right)
$$

where $\alpha_{k}$ - coefficient, which depends on cross section form of the beam (for rectangular $\alpha_{k} \cong 1.2$ ); $I=\frac{b b^{3}}{12}-$ moment of inertia of beam cross section. True elastic modulus at bending $E_{f}^{t}$ is bonded with fictitious modulus $E_{f}=\frac{P \cdot l_{i}^{3}}{48 \cdot I \cdot \omega_{\max }}$ in the following ratio

$$
\frac{1}{E_{f}}=\frac{1}{E_{f}^{t}}+\frac{1.2}{G} \cdot\left(\frac{h}{l_{i}}\right)^{2}
$$

The higher ratio of thickness of the specimen to its length $\frac{b}{l_{i}}$ and the higher degree of anisotropy of composite material, characterized by $\frac{E_{f}^{t}}{G}$, the more different true elastic modulus from fictitious.

With one test it is impossible to calculate elastic modulus by formula (1) as it has two unknowns $E_{f}$ and $G$. So for their determination are tested several specimens with different ratios $\left(\frac{b}{l_{i}}\right)$ and then was diagram made, where on the horizontal axis was put off value $\left(\frac{h}{l_{i}}\right)^{2}$ and on the vertical axis $-\frac{1}{E_{f}}$. In this coordinates, relation (2) has to be represented as a straight line, which crosses the vertical axis at the point $\frac{1}{E_{f}^{t}}$ and slope of this line to the horizontal axis equal $\frac{1.2}{G}$. Then value of $E_{f}^{t}$ and $G$ are determined by method of least square.

\section{DISCUSSION OF RESULTS}

$\mathrm{T}$

ension test results of highly filled fiberglass specimens (Direct "E" roving 0.7 - orthophthalic polyester resin 0.3 ) are in the Tab. 1.

\begin{tabular}{ccc}
\hline Temperature, ${ }^{\circ} \mathrm{C}$ & $\begin{array}{c}\text { Tensile strength at break } \\
\sigma_{\mathrm{b}} \mathrm{MPa}\end{array}$ & $\begin{array}{c}\text { Young's modulus in tension } \\
\text { E, GPa }\end{array}$ \\
-30 & 922.1 & 34.2 \\
0 & 980.2 & 36.8 \\
+22 & 987.1 & 47.8 \\
+40 & 690.5 & 38.8 \\
+50 & - & 37.4 \\
\hline
\end{tabular}

Table 1: Unidirectional fiberglass (Direct "E" roving 0.7 - orthophthalic polyester resin 0.3 ) properties at tension test [3]. 
According to the table, highest values of the characteristics are at test at room temperature. When temperature is lower or higher, then room temperature, characteristic value decreases. Strength at $50^{\circ} \mathrm{C}$ couldn't be determined.

In the Tab. 2 there are three-point bending test results of highly filled fiberglass specimens (Direct "E" roving 0.7 orthophthalic polyester resin 0.3). It should be noted, that this method allows getting more characteristics: to Young's modulus $\mathrm{E}$ and to longitudinal strength $\sigma_{\mathrm{b}}$ are added interlayer shear modulus $\mathrm{G}$ and shear strength $\tau_{\mathrm{b}}$. There were no problems with testing at various temperatures. However, this method is more sensitive to the quality of the test. In [1] there are range of parameters, which influence on results: slide from brackets, optimal ratio $h / l_{i}$, and edge effects. There are no clear tendencies of temperature effects. Value of normal strength is lower on $20-25 \%$, then values which were got at tensile tests. Influence of shear components on comparable $\left(\mathrm{E}, \sigma_{\mathrm{b}}\right)$ characteristics is clearly noticeable.

\begin{tabular}{ccccc}
\hline $\begin{array}{c}\text { Temperature, } \\
{ }^{\circ} \mathrm{C}\end{array}$ & $\mathrm{E}, \mathrm{GPa}$ & $\mathrm{G}, \mathrm{MPa}$ & $\sigma_{\mathrm{b}}, \mathrm{MPa}$ & $\tau_{\mathrm{b}}, \mathrm{MPa}$ \\
-30 & 40.4 & 762 & 682 & 24 \\
+22 & 30.7 & 924 & 674 & 32 \\
+50 & 35.7 & 1142 & 489 & 38 \\
\hline
\end{tabular}

Table 2: Unidirectional fiberglass (Direct "E" roving 0.7 - orthophthalic polyester resin 0.3 ) properties at bending tests

\section{FEATURES OF FAILURE}

11 tested unidirectional fiberglass specimens at uniaxial tensile, regardless of the temperature, failed like it is shown on Fig. 6. This type of failure is typical for fiber exfoliation and complete matrix destruction. Obviously, is the presence of shear deformation, which was not taken into account at stress calculation. This kind of failure may be associated with the grip construction without crimping.

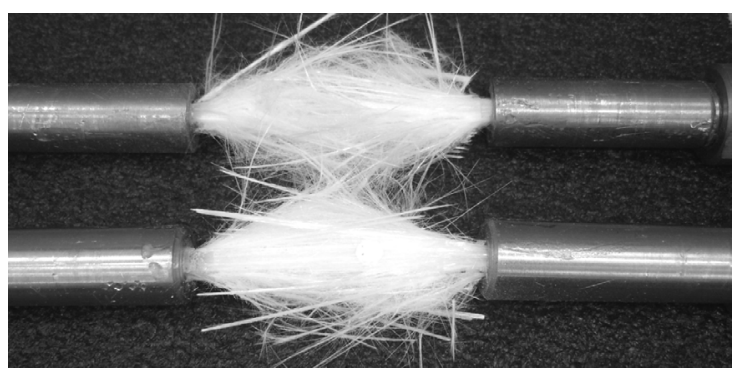

Figure 6: Failed unidirectional fiberglass (Direct "E" roving 0.7 - orthophthalic polyester resin 0.3) specimens after uniaxial tensile tests.

The same influence of specimen and grip construction was also noted in the paper [4] when was used NOL-method for getting characteristics of unidirectional fiberglass, Fig. 7, a. However, preliminary cyclic loading leaded to qualitative change in the type of failure (Fig. 7, b), whereas specimen and grip construction wasn't changed.

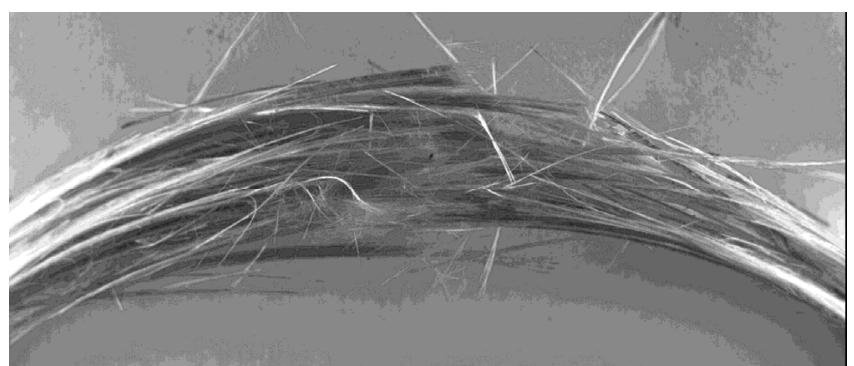

(a)

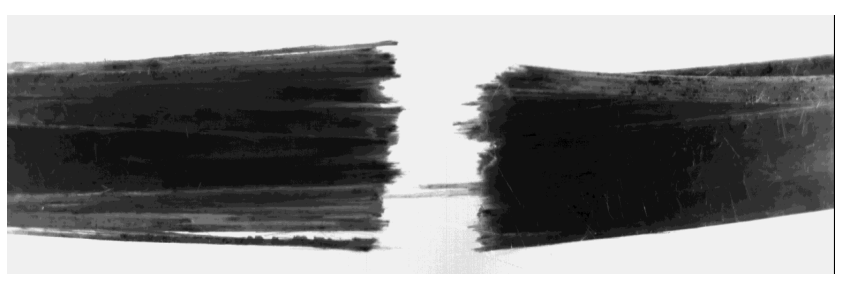

(b)

Figure 7: RBN 1680-UP 2217 fiberglass failure at static deformation by rigid half-discs (a) and after cyclic loading (b). 
On Fig. 8 are shown types of failure of beam specimens at three point bending tests on large (a) and small (b) bases. Clearly seen failure character: on long base - from normal stresses at tearing and crushing of fibers; on short base mainly on in-plain shear, perpendicular to the plain of loading.

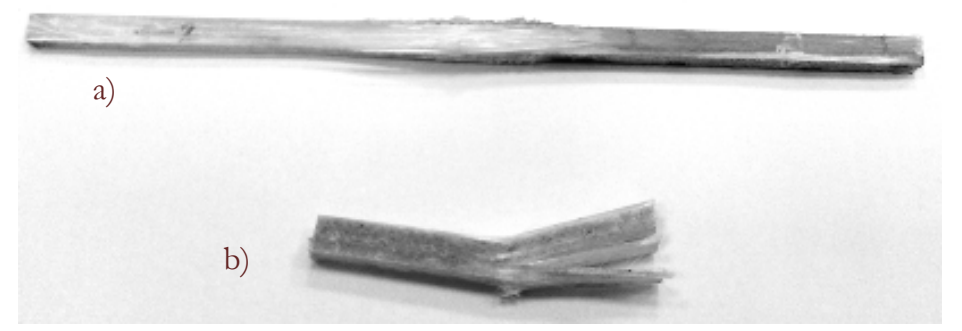

Figure 8: Failed unidirectional fiberglass (Direct "E" roving 0.7 - orthophthalic polyester resin 0.3 ) at three point bending tests on large (a) and small (b) bases.

\section{CONCLUSION}

7 hus, the identified properties of unidirectional fiberglass in two ways: in the direction of the tensile reinforcement and in three-point bending at different bases. Tests were carried out at normal, high and low temperatures. Values of comparable properties are close, but obvious tendency of temperature effect at tensile tests doesn't confirm at bending tests. Strength of normal separation, measured at bending testing, is lower on $20-25 \%$ than strength, measured at tensile testing. Both test methods are forced to differ from standard methods. At tensile tests were used grips without lateral compression of specimen material or with uniform pliable compression, which is caused by wedge effect. Bending tests can determine more characteristics, are not critical to changes of temperature and use improved theory of bending. Type of failure of unidirectional fiberglass at tensile tests along reinforcement is similar to the usage of NOL-method in the absence of damage accumulation. This type of failure suggests a significant influence of shear deformations. At three point bending tests specimen failed traditionally: on long bases - mainly from normal stresses, on short - from tangent.

\section{ACKNOWLEDGMENTS}

esearch were carried out on equipment of the Center of Experimental Mechanics of Perm National Research Polytechnic University with financial support from grant RFBR № 12-08-31336.

\section{REFERENCES}

[1] Y. M. Tarnopolsky, T. Y. Kintsis, Methods of static tests of reinforced plastics, Chemistry, Moscow (1981).

[2] A.V. Babushkin, V.E. Wildemann, D.S. Lobanov, Factory laboratory. Materials' diagnostics, 76(7) (2010) 57.

[3] D.S. Lobanov, A.V. Babushkin, In: Proc. of ECCM15: European Conference on Composite Materials, Venice, Italy, (2012), Paper ID: 1224. - ISBN 978-88-88785-33-2.

[4] A.V. Babushkin, A.V. Kozlova, Composites: Mechanics, Compositions, Applications. An International Journal, 2(3) (2011) 223. 